\title{
Diversity pattern of nitrogen fixing microbes in nodules of Trifolium arvense (L.) at different initial stages of ecosystem development
}

\author{
S. Schulz ${ }^{1}$, M. Engel ${ }^{1}$, D. Fischer ${ }^{1}$, F. Buegger ${ }^{2}$, M. Elmer ${ }^{3}$, G. Welzl ${ }^{1}$, and M. Schloter ${ }^{1}$ \\ ${ }^{1}$ Helmholtz Zentrum München, German Research Center for Environmental Health, Research Unit Environmental Genomics, \\ Ingolstädter Landstr. 1, 85764 Neuherberg, Germany \\ ${ }^{2}$ Helmholtz Zentrum München, German Research Center for Environmental Health, Institute of Soil Ecology, Ingolstädter \\ Landstr. 1, 85764 Neuherberg, Germany \\ ${ }^{3}$ Brandenburg University of Technology, Research Centre Landscape Development and Mining Landscapes, \\ Konrad-Wachsmann-Allee 6, 03046 Cottbus, Germany
}

Correspondence to: S. Schulz (stefanie.schulz@helmholtz-muenchen.de)

Received: 27 August 2012 - Published in Biogeosciences Discuss.: 21 September 2012

Revised: 31 January 2013 - Accepted: 31 January 2013 - Published: 22 February 2013

\begin{abstract}
Legumes can be considered as pioneer plants during ecosystem development, as they form a symbiosis with different nitrogen fixing rhizobia species, which enable the plants to grow on soils with low available nitrogen content. In this study we compared the abundance and diversity of nitrogen fixing microbes based on the functional marker gene nifH, which codes for a subunit of the Fe-protein of the dinitrogenase reductase, in nodules of different size classes of Trifolium arvense (L.). Additionally, carbon and nitrogen contents of the bulk soil and plant material were measured. Plants were harvested from different sites, reflecting 2 (2a) and 5 (5a) yr of ecosystem development, of an opencast lignite mining area in the south of Cottbus, Lower Lusatia (Germany) where the artificial catchment "Chicken Creek" was constructed to study the development of terrestrial ecosystems.

Plants from the 5a site revealed higher amounts of carbon and nitrogen, although nifH gene abundances in the nodules and carbon and nitrogen contents between the two soils did not differ significantly. Analysis of the nifH clone libraries showed a significant effect of the nodule size on the community composition of nitrogen fixing microbes. Medium sized nodules $(2-5 \mathrm{~mm})$ contained a uniform community composed of Rhizobium leguminosarum bv. trifolii, whereas the small nodules $(<2 \mathrm{~mm})$ consisted of a diverse community including clones with non-Rhizobium nifH gene sequences. Regarding the impact of the soil age on the community composition a clear distinction between the small and
\end{abstract}

the medium nodules can be made. While clone libraries from the medium nodules were pretty similar at both soil ages, soil age had a significant effect on the community compositions of the small nodules, where the proportion of $R$. leguminosarum bv. trifolii increased with soil age.

\section{Introduction}

As a result of global change, in the last century an increase in initial ecosystems can be observed worldwide. Initial ecosystems can evolve naturally for example during the retreat of glaciers or in response to human activities mainly in areas with opencast mining activities. Therefore, questions addressing food web dynamics, plant establishment and soil formation in initial ecosystems are not only of basic ecological interest but also of high commercial concern.

To address these issues an experimental catchment called "Chicken Creek" was constructed in the opencast lignite mining area in the south of Cottbus, Lower Lusatia (Germany) (Kendzia et al., 2008), which provides a unique opportunity to study initial ecosystem development. Already after five years of soil development, increasing complexity of food webs and increasing density of woody plants like birch, pine, and black locust was monitored (Elmer et al., 2011; Schaaf et al., 2010), which indicates a very fast progress in ecosystem development. 
In this respect, monitoring of the vegetation revealed that the legume Trifolium arvense (L.) appeared as one of the pioneering plants already after two years of ecosystem development. Its abundance steadily increased in the following years and peaked after four years (Elmer et al., 2011). Already after $5 \mathrm{yr}$ of ecosystem development significant concentrations of carbon in the soil developed, whereas the nitrogen pools remained low. These results underline the advantage of legumes in nitrogen poor ecosystems.

As legumes form symbiotic interactions with rhizobia, they are able to survive in soils with low amounts of available nitrogen as 75 and $90 \%$ of the nitrogen needed for growth is provided by the symbiotic partner (Jacot et al., 2000). Boswell et al. (2007) demonstrated that up to $11 \mathrm{~kg} \mathrm{Nha}^{-1} \mathrm{yr}^{-1}$ can enter the soil by symbiotic nitrogen fixation from $T$. arvense. However, the successful establishment of the symbiosis strongly depends on (i) the survival of the bacteria in bulk soil mainly during autumn and winter; (ii) the colonization of the rhizosphere of the host plant, which in the case of clover, is followed by root hair curling and the formation of an infection thread; and (iii) the intracellular infection and nodule development (Crespi and Gálvez, 2000; Sessitsch et al., 2002; Markmann and Parniske, 2009). These high numbers of different interim stages make the process prone to disturbances or environmental stresses. The majority of plants can only form a symbiosis with a restricted number of rhizobia for example Trifolium species preferably form a symbiosis with Rhizobium leguminosarum bv. trifolii, but for some exceptions it is known that they can be infected by different strains. For example Phaseolus can be infected by $R$. leguminosarum species and by Burkholderia (Doyle, 1998; Gyaneshwar et al., 2011). Furthermore, it has been often postulated that the inter- and intra-species diversity of rhizobia, which are able to form nodules with selected legumes, strongly depend on environmental conditions like soil $\mathrm{pH}$ and water content or biogeography. For example, it was shown that $R$. etli as microsymbiont of beans can be replaced by $R$. tropici under acidic conditions (Anyango et al., 1995; Sadowsky and Graham, 2006) and that diversity of rhizobia infecting chickpea (Alexandre et al., 2009) or Lotus corniculatus (Sotelo et al., 2011) depends on the investigated biogeographic region. Moreover, annual legumes like T. arvense face the problem that the symbiosis must be established each year again (Sessitsch et al., 2002). However, with each passing year the rhizobial population might increase, as they are released from the nodules at the end of each growing season (Sadowsky and Graham, 2006) dominated by those ecotypes which form the most efficient symbiosis related to the particular plant cultivar and the given environmental conditions.

In this study we compared the diversity of nitrogen fixing microbes associated with $T$. arvense (L.) at the "Chicken Creek" catchment collected from nodules from a site $2 \mathrm{yr}$ (2a) after initial ecosystem development started, where $T$. arvense recently appeared (density below $5 \%$ ), and a site
$5 \mathrm{yr}(5 \mathrm{a})$ after initial ecosystem development started, where the clover revealed a density of up to $25 \%$ (Elmer et al., 2011). We characterized the diversity of nitrogen fixing microbial communities in the nodules by targeting the nifH gene, which codes for the Fe-protein of the dinitrogenase reductase. To further characterize the analyzed plants and nodules, we measured the nifH gene abundance in the same nodules, carbon and nitrogen content of the plants, the nodule numbers and different soil parameters. Due to the higher environmental stress level at the very beginning of ecosystem development and the enrichment of effective $R$. leguminosarum ecotypes because of the successive presence of $T$. arvense, we expected that the level of intraspecies diversity of $R$. leguminosarum nodulating clover will change with ongoing succession, being more diverse at the beginning of ecosystem development.

\section{Material and methods}

\subsection{Sampling site}

Samples were taken from two sites directly adjacent to the artificial catchment "Chicken Creek", which is located in an opencast lignite mining area in the south of Cottbus, Lower Lusatia $\left(51^{\circ} 36^{\prime} \mathrm{N}, 14^{\circ} 16^{\prime} \mathrm{E}\right)$. This region is characterized by a sub-continental climate with a mean annual temperature of $8.9^{\circ} \mathrm{C}$ and relatively low annual precipitation with $563 \mathrm{~mm}$ (Gerwin et al., 2009).

The catchment has a size of 6.5 ha and was composed of a sandy substrate $(84.8 \%$ sand, $9.1 \%$ silt, $6.1 \%$ clay $)$ from Pleistocene sediments, which were deposited as terminal moraine during the Saale-glacial period. Below the sandy surface a base layer of Tertiary clay was constructed as a barrier for seepage water. Further details about the technical construction and the initial conditions are given by Gerwin et al. (2009) and Kendzia et al. (2008). The construction of the catchment was finished in September 2005, which was therefore defined as "point zero" for ecosystem development.

The sampling site in the east of the Chicken Creek was constructed as part of the catchment and has thus the same development stage. Plant coverage was between 25 and $35 \%$. The dominant plant species were Trifolium arvense, Calamagrostis epigejos, Echium vulgare, Daucus carota and Cirsium arvense. The second site in the west of the Chicken Creek was restored to "point zero" in 2008, thus the progress of soil development is three years behind the artificial catchment. Only 5 to $10 \%$ of the site was covered with vascular plants. Dominant plant species were Conyza canadensis, Tussilago farfara, Calamagrostis epigejos, Echium vulgare and Trifolium arvense (Elmer et al., 2011). At both sites three plots $(3 \times 3 \mathrm{~m})$ were selected. Each subplot was $50 \mathrm{~m}$ apart from each other. 


\subsection{Sampling procedure and sample preparation}

Sampling took place in July 2010. Thus, the eastern site had an age of $5 \mathrm{yr}(5 \mathrm{a})$ and the western an age one of $2 \mathrm{yr}(2 \mathrm{a})$. From each plot three Trifolium arvense (L.) plants at the flowering stage and bulk soil $(0-5 \mathrm{~cm})$ samples were taken. Plants were separated in green biomass and roots. The aboveground biomass was used to determine the carbon and nitrogen content. The roots were directly rinsed with sterile water and nodules from all plants were counted and classified in three groups of different size $(<2 \mathrm{~mm}, 2-5 \mathrm{~mm}$, and $>5 \mathrm{~mm}$ ). Afterwards all nodules were surface sterilized by incubating the nodules for 5 min with $1 \%$ Chloramin T (AppliChem, Germany) and three times rinsing with sterile water for $5 \mathrm{~min}$ (Singh, 1992). Sterility was tested by dipping the nodules on LB agar plates followed by an incubation of the plates for $48 \mathrm{~h}$ at $30^{\circ} \mathrm{C}$. Afterwards nodules were directly frozen at $-20^{\circ} \mathrm{C}$. Bulk soil samples were stored at $4{ }^{\circ} \mathrm{C}$ for subsequent soil chemical analysis.

\subsection{Chemical analysis of soil and plant samples}

Each individual plant and bulk soil material was dried at $65^{\circ} \mathrm{C}$ for 2 days. Afterwards, it was ball milled (Retsch MM2, Retsch GmbH, Germany) and $1.5 \mathrm{mg}$ plant material and $80 \mathrm{mg}$ soil were weighted into $3.3 \times 5 \mathrm{~mm}$ and $5 \times 9 \mathrm{~mm}$ tin capsules (IVA Analysentechnik, Germany), respectively. The total carbon and nitrogen contents were measured with the Elemental-Analysator "Euro-EA" (Eurovector, Italy).

Nitrate $\left(\mathrm{NO}_{3}^{-}-\mathrm{N}\right)$, ammonium $\left(\mathrm{NH}_{4}^{+}-\mathrm{N}\right)$, dissolved organic carbon (DOC) and nitrogen (DON) of all soil samples were determined in $\mathrm{CaCl}_{2}$ extracts. For the extraction, $20 \mathrm{~g}$ of fresh soil was overhead shaken for $45 \mathrm{~min}$ with $20 \mathrm{~mL}$ $0.01 \mathrm{M} \mathrm{CaCl}_{2}$. Afterwards, the extracts were filtered through a Millex HV Millipore filter (pore size, $0.45 \mu \mathrm{m}$ ). Nitrate, ammonium and DON were determined by continuous flow analysis with a photometric autoanalyzer (CFA-SAN Plus, Skalar Analytik, Germany). DOC was determined with the DIMA-TOC 100 (Dima Tec, Germany).

\subsection{Nucleic acid extraction from nodules}

For nucleic acid extraction, from three plants per plot a small $(<2 \mathrm{~mm})$ and a medium $(2-5 \mathrm{~mm})$ sized nodule was used. The three nodules from the same size class were pooled and DNA was extracted by thermolysis. Plants from the three different plots were treated as true replicates. Nodules were crushed under sterile conditions with a pestle in $300 \mu \mathrm{L}$ lysis buffer (Krasova-Wade and Neyra, 2007). The lysis buffer consisted of $0.2 \mathrm{mg} \mathrm{mL}^{-1}$ ProteinaseK (Biozym, Germany), $0.05 \%$ Tween20 (Sigma, Germany) and $10 \%$ Taq Polymerase PCR-Buffer (Invitrogen, Germany). Afterwards, samples were incubated for $1 \mathrm{~h}$ at $55^{\circ} \mathrm{C}$ and $10 \mathrm{~min}$ at $95^{\circ} \mathrm{C}$. Cell debris were centrifuged for $5 \mathrm{~min}$ at $16000 \mathrm{~g}$ (modified after Sambrook and Russell, 2001) The quantity of DNA in the supernatant was checked with a spectrophotometer (Nanodrop, PeqLab, Germany). Afterwards, samples were frozen at $-20^{\circ} \mathrm{C}$. The obtained DNA extracts were used for the quantification of the nifH gene abundance and the preparation of nifH gene clone libraries.

\subsection{Quantitative real-time PCR of the nifH gene}

Quantitative real-time PCR was conducted on a 7300 RealTime PCR System (Applied Biosystems, Germany) using SybrGreen as fluorescent dye. For the quantitative real-time PCR (qPCR) nifH primers described by Rösch et al. (2002) were applied, which produced a 458 bp PCR fragment. As standard curve a serial dilution $\left(10^{2}\right.$ to $10^{7}$ copies $\left.\mu \mathrm{L}^{-1}\right)$ of a plasmid containing the nifH gene fragment of Azospirillum irakense DSM 11568 was used. The reaction mixture consisted of $12.5 \mu \mathrm{L}$ Power SybrGreen Master Mix (Applied Biosystems, Germany), $0.12 \mu \mathrm{M}$ of each primer (Metabion, Germany), $0.5 \mu \mathrm{L}$ of $3 \%$ bovine serum albumin (Sigma, Germany), and $2 \mu \mathrm{DNA}$. The reaction volume was adjusted to $25 \mu \mathrm{L}$ with nuclease-free water. The thermal profile was as follows: a $10 \mathrm{~min}$ hot start at $95^{\circ} \mathrm{C}$, followed by 40 repetitions of $45 \mathrm{~s}$ at $95^{\circ} \mathrm{C}, 45 \mathrm{~s}$ at $55^{\circ} \mathrm{C}$ and $45 \mathrm{~s}$ at $72^{\circ} \mathrm{C}$ (Töwe et al., 2010). For confirming specificity of the amplicons after each PCR run a melting curve and a $2 \%$ agarose gel were conducted. The amplification efficiency was calculated with the equation $\mathrm{Eff}=\left[10^{(1 / \text {-slope })}-1\right]$ and resulted in $83 \%$.

\subsection{Preparation of nifH gene clone libraries and sequencing}

In total 12 clone libraries were prepared ( 2 sites, 2 nodule sizes, and 3 plots). For the amplification of nifH the same primers as for the $\mathrm{qPCR}$ were used. The reaction mixture consisted of $2.5 \mu \mathrm{L}$ TopTaq buffer, $5 \mu \mathrm{L}$ Q-Solution, $2.5 \mu \mathrm{L}$ of $2 \mathrm{mM}$ dNTPs (Fermentas, Germany), $0.2 \mu \mathrm{M}$ of each primer (Metabion, Germany), $0.5 \mu \mathrm{L}$ BSA (3\%), $1 \mu \mathrm{L}$ TopTaq Polymerase (Qiagen, Germany) and $1 \mu \mathrm{L}$ DNA. The reaction volume was adjusted to $25 \mu \mathrm{L}$ with nuclease-free water. The thermal profile was as follows: a $10 \mathrm{~min}$ hot start at $94^{\circ} \mathrm{C}$, followed by 35 repetitions of $45 \mathrm{~s}$ at $94^{\circ} \mathrm{C}, 45 \mathrm{~s}$ at $57^{\circ} \mathrm{C}, 45 \mathrm{~s}$ at $72{ }^{\circ} \mathrm{C}$ and a final prolongation of $10 \mathrm{~min}$ at $72^{\circ} \mathrm{C}$. The PCR products were then checked for the right size of $458 \mathrm{bp}$ and cleaned up with the Qiagen PCR Purification Kit.

For cloning and transformation the Zero Blunt ${ }^{\circledR}$ Topo ${ }^{\circledR}$ Cloning Kit (Invitrogen, Germany) was used as recommended by the manufacturer. After the transformation, 30 clones per sample were cultivated overnight in $5 \mathrm{~mL}$ LB containing $50 \mu \mathrm{g} \mathrm{mL}^{-1}$ kanamycin. Plasmids were isolated with the NucleoSpin ${ }^{\circledR}$ Plasmid Kit (Macherey Nagel, Germany) and inserts were checked for the right size by EcoRI digestion (Fermentas, Germany). Finally, clones with the right size were used for sequencing.

Inserts were sequenced on the ABI PRISM ${ }^{\circledR} 3730$ DNA Sequencer (Applied Biosystems, USA) using the BigDye 
Table 1. Chemical parameters of bulk soil and plants. Dissolved organic carbon (DOC), dissolved organic nitrogen (DON), total carbon (TC) and total nitrogen (TN) contents were measured in bulk soil samples from the $2 \mathrm{a}$ and the $5 \mathrm{a}$ site $(n=3$, standard deviations in parenthesis). Plant carbon and nitrogen contents were measured in Trifolium arvense (L.) from the $2 \mathrm{a}$ and the 5a site $(n=9$, standard deviations in parenthesis). Nitrate concentration was below the detection limit for all samples $\left(<0.3 \mu \mathrm{g} \mathrm{g}^{-1}\right)$. A significant impact of soil age on the measured parameters was tested with one-factor ANOVA $(p<0.05)$ and indicated by an asterisk.

\begin{tabular}{rrrrrr|rrr}
\hline & \multicolumn{3}{c}{ soil $\left[\mu \mathrm{gg}^{-1}\right]$} & \multicolumn{3}{c}{ plant [\%] } \\
\cline { 2 - 9 } & $\mathrm{NH}_{4}^{+}$ & DON & $\mathrm{TN}$ & DOC & TC & $\mathrm{C}^{*}$ & $\mathrm{~N}^{*}$ & $\mathrm{C} / \mathrm{N}$ \\
$\mathrm{n}$ & $0.04(0.02)$ & $0.33(0.03)$ & $5.91(2.54)$ & $3.04(0.64)$ & $137(8.44)$ & $37.1(4.7)$ & $1.68(0.3)$ & $22.3(2.9)$ \\
$5 \mathrm{a}$ & $0.02(0.003)$ & $0.46(0.12)$ & $8.01(0.93)$ & $3.53(0.38)$ & $149(3.09)$ & $41.4(1.0)$ & $2.16(0.46)$ & $19.9(3.9)$ \\
\hline
\end{tabular}

Terminator v3.1 Cycle Sequencing Kit (Applied Biosystems). The sequencing reaction consisted of $2 \mu \mathrm{L}$ Buffer Descriptor Table Buffer, $2 \mu \mathrm{L}$ Big Dye Terminator v3.1 Mix, $1 \mu \mathrm{L}$ M13 forward sequencing primer (10 pmol), $100 \mathrm{ng}$ DNA and was adjusted with nuclease free water to a final volume of $10 \mu \mathrm{L}$. The thermal profile started with $1 \mathrm{~min} 96^{\circ} \mathrm{C}$ and was followed by 35 repetitions of $15 \mathrm{~s}$ at $96^{\circ} \mathrm{C}, 15 \mathrm{~s}$ at $50^{\circ} \mathrm{C}$ and 4 min at $60^{\circ} \mathrm{C}$.

\subsection{Phylogenetic analysis}

Sequences were verified using the BioEdit Sequence Alignment Editor v. 7.1.3. (Hall, 1999). Nucleotide sequences were translated into protein sequences with the ExPASy Translate Tool (http://web.expasy.org/translate/), and BlastX was used to confirm that the sequence codes for NifH. All sequences including stop codons or deletions were omitted from further analyses. In total, 233 sequences were used for further analyses, wherefrom 114 originated from the $2 \mathrm{a}$ site and 119 from the 5a site. Sequence alignments, construction of the phylogenetic tree and calculation of a distance matrix was done with the ARB software package (www.arb-home.de) (Ludwig et al., 2004). For the phylogenetic analyses of the nifH transcripts, we used the updated nifH database from Zehr et al. (2003) (http://www. es.ucsc.edu/ $\sim$ wwwzehr/research/database/). Sequences were imported to the databases, and the alignments were checked and manually corrected. The phylogenetic tree was calculated by applying the neighbor-joining algorithm (Saitou and Nei, 1987) (1000 bootstrap replications). All phylogenetic analyses were done on DNA level as strongly related nifH sequences can be expected in clone libraries from nodules (Opperdoes and Lemey, 2009).

Calculations of operational taxonomic units (OTU) were done with mothur vs. 1.26.0. (Schloss et al., 2009). As estimators for diversity and evenness the Invsimpson and the Shannon evenness index were applied, respectively. The Invsimpson index is the inverse (Invsimpson $=1 / D$ ) of the classical Simpson diversity index (D), which is calculated by the formula $D=\sum\left(n_{\mathrm{i}}\left(n_{\mathrm{i}}-1\right)\right) /(n(n-1))$, where $n_{\mathrm{i}}$ is the number of individuals in the i-th OTU and $n$ is the total number of individuals in the community.
The Shannon evenness $\left(E_{H}\right)$ is based on the Shannon diversity index $\left(H^{\prime}=-\sum\left(p_{\mathrm{i}}\right)\left(\ln p_{\mathrm{i}}\right)\right)$ and is calculated as follows: $E_{H}=H^{\prime} / \ln S$, where $\mathrm{S}$ is the total number of individuals and $p_{\mathrm{i}}$ is the number of individuals in the i-th OTU.

Retrieved unique nifH nucleic acid sequences are available at the GenBank database under the Accession No JX501529_ JX501657. For details about the clones comprising identical sequences see Table S1 in the Supplement.

\subsection{Statistic}

Statistical analyses were carried out with the R environment (http://www.r-project.org). Prior to analysis, data were tested for normal distribution by Q-Q plots and the KolmogorovSmirnoff test. If necessary data were $\log$ transformed prior to further analysis. Soil and plant parameter were tested for significant differences by one-factor ANOVA. Gene abundance data and the amount of the differently sized nodules per plant were tested by two-factor ANOVA. Pairwise comparisons between the different nodule size classes were done with $t$-tests, which were corrected for multiple testing with the Holm method. The influence of soil age and nodule size on the nifH gene diversity was tested on the basis of the distance matrix with Adonis, implementing 999 permutations.

\section{Results}

\subsection{Chemical analysis of soil and plant samples}

Analyses of both soils revealed only little differences in carbon and nitrogen contents, which were not statistically significant. However, by tendency total carbon (TC) and nitrogen $(\mathrm{TN})$ concentrations were higher in soil samples from the $5 \mathrm{a}$ site compared to the $2 \mathrm{a}$ site. However, whereas TN content was 1.4 times higher in the soil samples from the 5a site $\left(5.91 \mu \mathrm{g} \mathrm{g}^{-1}\right.$, respectively $\left.8.01 \mu \mathrm{g} \mathrm{g}^{-1}\right)$, the total carbon content increased only about a factor of 1.1 from 137 (2a) to $149{\mu \mathrm{g} \mathrm{g}^{-1}}$ (5a), resulting in a decreased $\mathrm{C} / \mathrm{N}$ ratio in soil samples from the $5 \mathrm{a}$ site. The nitrate concentrations were below the detection limit for both soils $\left(<0.3 \mu \mathrm{g} \mathrm{g}^{-1}\right)$. Also ammonium concentrations were low, however higher values were measured in the $2 \mathrm{a}$ soil, reaching $0.04 \mu \mathrm{g} \mathrm{g}^{-1}$ 


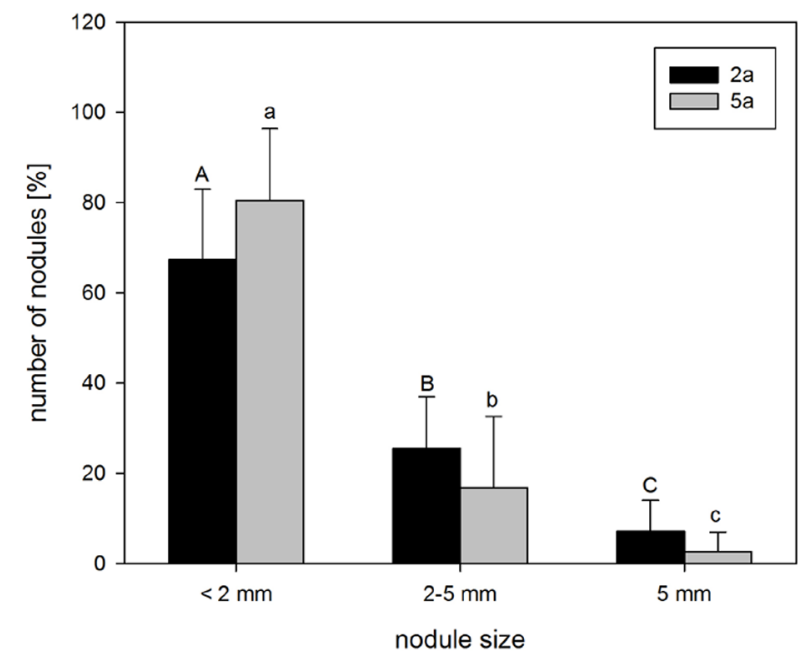

Fig. 1. Distribution of the different nodule size classes. Nodules from each site were grouped after their size in three classes: $<2 \mathrm{~mm}$ (small), 2-5 mm (medium) and $>5 \mathrm{~mm}$ (large) $(n=9$, error bars represent standard deviations). Significant differences between the three nodule size classes are indicated by different capital letters for the 2a site and by small letters for the 5a site. Pairwise comparisons were done with a $t$-test where the Holm method was applied for multiple testing.

compared to $0.02 \mu \mathrm{gg}^{-1}$ in soil samples from the $5 \mathrm{a}$ site. In contrast dissolved organic nitrogen (DON) was higher in the $5 \mathrm{a}$ soil reaching $0.46 \mu \mathrm{g} \mathrm{g}^{-1}$. Dissolved organic carbon (DOC) concentrations did were in the range of $3.04 \mu \mathrm{g} \mathrm{g}^{-1}$ to $3.53 \mu \mathrm{g} \mathrm{g}^{-1}$. Although slight differences in soil parameter were detectable between both sites they were not significant.

Parallel to the higher DON and DOC values in the 5a soil, plants from the 5a site comprised significantly higher carbon and nitrogen contents, $41.4 \%$ carbon and $2.16 \%$ nitrogen compared to 37.1 and $1.68 \%$. However, as both, carbon and nitrogen, increased, the $\mathrm{C} / \mathrm{N}$ ratio of the plants did not differ significantly between both sites. Data are summarized in Table 1.

\subsection{Distribution of nodules}

In total 297 nodules of an indeterminate shape were collected from 18 plants, 154 from the 2a site and 143 from the 5a site. Nodules were classified into three classes: (i) small nodules $(<2 \mathrm{~mm})$, (ii) medium nodules $(2-5 \mathrm{~mm})$, and (iii) large nodules $(>5 \mathrm{~mm})$. The distribution of the nodules is shown in Fig. 1. Overall, the amount of nodules significantly decreased with their size $(p<0.001)$. Thus, small nodules, made up $67 \%$ (107 nodules) in plants derived from the 2a soil and $80 \%$ (116) in plants derived from the 5a soil. Consequently, more medium and large nodules were collected from plants from the 2a site comprising 26 and $7 \%$, respectively, while from plants sampled from the 5a site only 17 and $3 \%$ belonged to the medium and large sized nodule class.

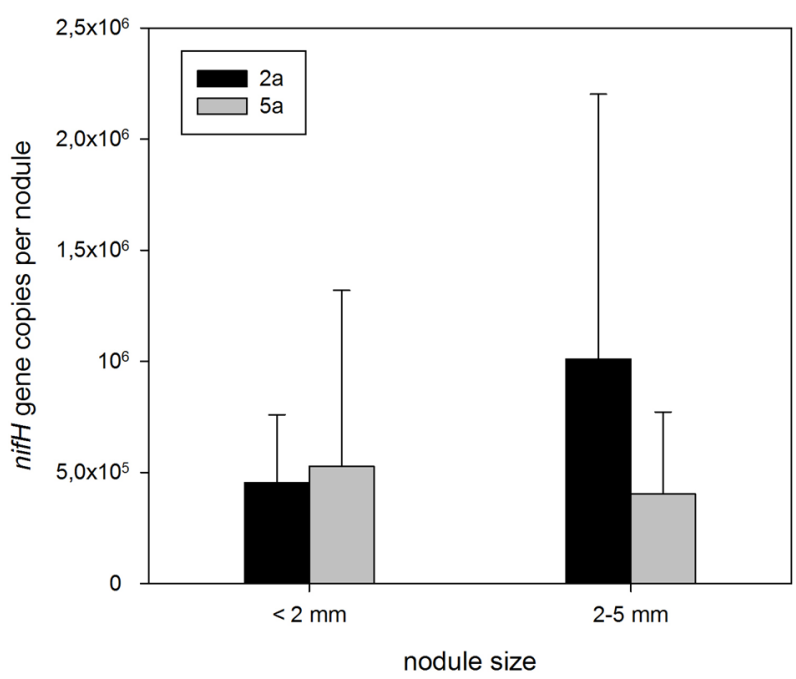

Fig. 2. Copy numbers per nodule of the functional gene nifH. Gene abundances were measured in small and medium sized nodules from the $2 \mathrm{a}$ and the $5 \mathrm{a}$ site $(n=3$, error bars represent standard deviations).

\subsection{Abundance of nifH genes in the nodules}

The amount of nifH gene copies per nodule is shown in Fig. 2. Overall, the nifH gene abundance ranged around $5 \times 10^{5}$ copies per nodule in the small nodules independent from the site the plants were sampled. Regarding the medium nodules, similar values were measured for plants grown on the 5a soil, whereas nifH gene copy numbers per nodule were 2.5 times higher in the nodules from the 2a site. However, as the values strongly fluctuated no significant influence of soil age or nodule size was detected.

\subsection{Phylogenetic diversity of nodule associated diazotrophs}

The analysis of rarefaction curves on the $97 \%$ DNA homology level revealed no differences in the diversity of nifH harboring microbes in medium sized nodules from plants grown on the two different sites. At that similarity level the maximum number of OTUs per group of nodules was 3 (Fig. 3). When the rarefaction curves were analyzed on a $99 \%$ similarity level for the medium sized group of nodules up to 6 OTUs for nodules from plants grown on the 2a site were detected, whereas the number of OTUs from the group of nodules grown on the 5a site were significantly lower (3 OTUs). These data indicate a higher diversity in the medium sized nodules grown on the younger site. Overall the diversity of nifH harboring microbes was bigger in the small nodules than in the medium sized nodules, where up to 10 OTUs (on a $99 \%$ similarity level) were be detected. In contrast to the data described for the group of medium sized nodules, the number of OTUs from the group of nodules that were assigned to the small size class was higher in plants grown on 
the 5a site. As the number of analyzed clones was too low for nodules of the small class from plants grown on the 5a site as well as for nodules of the medium size class grown on the 2a site to reach full coverage, which is needed for a quantitative diversity assessment, the following analytic steps were performed on a $97 \%$ homology level.

Based on this $97 \%$ homology calculation, all obtained nifH sequences were distributed among 9 OTUs (Table 2). In the clone libraries from the medium sized nodules and from the group of small sized nodules from plants grown on the $2 \mathrm{a}$ site, sequences clustered in three OTUs each. In contrast, calculations resulted in six OTUs for the sequences of the group of small nodules from plants grown on the 5a site.

Adonis calculations revealed a significant influence of the nodule size $(p=0.001)$ on the nifH gene diversity. While highest diversity was estimated for nodules from plants sampled on the 5a site covering 6 OTUs and resulting in an Invsimpson value of 3.59 , the sequences were evenly distributed among three OTUs for the small nodules from the 2a site. As a result clone libraries of the small nodules from the two sites were significantly different $(p=0.048)$. In contrast to the small nodules, clone libraries from the medium nodules were very similar $(p=0.745)$ and diversity and evenness were very low, as more than $95 \%$ of the sequences clustered in OTU5.

The phylogenetic affiliation of the nifH gene sequences, as depicted in Fig. 4, revealed that two main clusters were formed. From all sequenced clones 24 fell in Cluster I, while 209 could be assigned to Cluster II, which were interspersed throughout OTU5-8. Generally, Cluster II was composed of Rhizobium and Sinorhizobium, but all sequences exhibited strong homology with Rhizobium leguminosarum bv. trifolii. Despite the high similarity to R. leguminosarum bv. trifolii, sequence variations among the OTUs ranged from 100 to $92.4 \%$ similarity. Surprisingly besides sequences which were closely related to rhizobial nifH sequences, the OTUs, which could be assigned to cluster I, were closely related to Bradyrhizobia, Burkholderia, Leptothrix and Azospirillum. Based on the phylogenetic affiliation it is very likely that OTU9 is homolog to Azospirillum. OTU1-4 were assigned to a very diverse subcluster composed of Azospira, Stenotrophomas and Burkholderia, Azoarcus and Leptothrix, which made a clear affiliation almost impossible.

\section{Discussion}

A lot of research has been done on legume-Rhizobium symbiosis in the last century mainly in the context of agriculture to improve efficiency of plant microbe interactions with the aim to enhance yields (Fischer et al., 2012; Perrineau et al., 2011; Naeem et al., 2004). However, little is known about that interaction of rhizobia and legumes in initial ecosystems, where nutrients and microbial biomass are low and inoculation with Rhizobium strains does not occur. Consequently, in
Table 2. Distribution of sequences among different operational taxonomic units (OTU). In total sequences were consolidated in 4 groups: 2a small, 2a medium, 5a small and 5a medium. The subsequent classification of sequences in different OTUs was done with mothur v. 1.26.0. on a $97 \%$ similarity level for each sample individually. As indices for diversity and evenness the Invsimpson index and the Shannon Evenness index were applied, respectively.

\begin{tabular}{lrrrr}
\hline & \multicolumn{4}{c}{ Number of sequences } \\
\cline { 2 - 5 } OTU & 2a small & 2a medium & 5a small & 5a medium \\
\hline 1 & 13 & 2 & - & - \\
2 & - & - & 6 & - \\
3 & - & - & 1 & - \\
4 & - & - & - & 1 \\
5 & 15 & 74 & 19 & 77 \\
6 & - & - & 6 & - \\
7 & 9 & 1 & 6 & - \\
8 & - & - & 2 & - \\
9 & - & - & - & 1 \\
Invsimpson & 3.08 & 1.08 & 3.59 & 1.05 \\
Shannon Evenness & 0.98 & 0.17 & 0.72 & 0.12 \\
\hline
\end{tabular}

these ecosystems the success of a symbiosis depends on the indigenous rhizobial community being already present in the soil. Therefore, it was the aim of this study to compare the diversity of nifH carrying diazotrophs in the nodules of the pioneering clover Trifolium arvense (L.), taken from a $2 \mathrm{yr}$ (2a) and a 5 yr (5a) old soil. Both sites developed under similar climatic conditions and from the same starting material, thus these effects as drivers for the observed differences in diversity pattern could be excluded.

As we were especially interested in rhizobia, which have the potential to fix atmospheric $\mathrm{N}_{2}$, this study focused on the analysis of the nifH gene instead of other housekeeping genes or genes involved in nodulation (Sotelo et al., 2011; Rogel et al., 2011; Talbi et al., 2010). Thus, we can exclude that nod $^{+}$ but nifH $^{-}$rhizobia were investigated, which are not advantageous for the nitrogen budget of the host plant. Moreover, analyses were done on the level of DNA to distinguish sequences of closely related biovars. For example NifH of $R$. leguminosarum bv. trifolii and viciae bv. share $95 \%$ of the amino acids, while on DNA level similarity of nifH is below $85 \%$.

Measurements of the nitrogen content of the plants showed that the clover from the 5a site exhibited significantly higher nitrogen concentrations, although $\mathrm{DON}$ and $\mathrm{NH}_{4}^{+}$did not differ significantly between the two soils. Therefore, higher nitrogen contents can be related to higher nitrogen fixation rates, which might be a fact of higher number of nodules per plant or a generally higher activity of nitrogen fixing microbes. Voisin et al. (2010) showed that nodule formation is induced under nitrate limitation and as no nitrate was detectable at both sites, it is not surprising that plants developed a relatively high number of nodules. In average, 16 nodules per plant were detected, which is comparable or even higher than in other studies where systems 


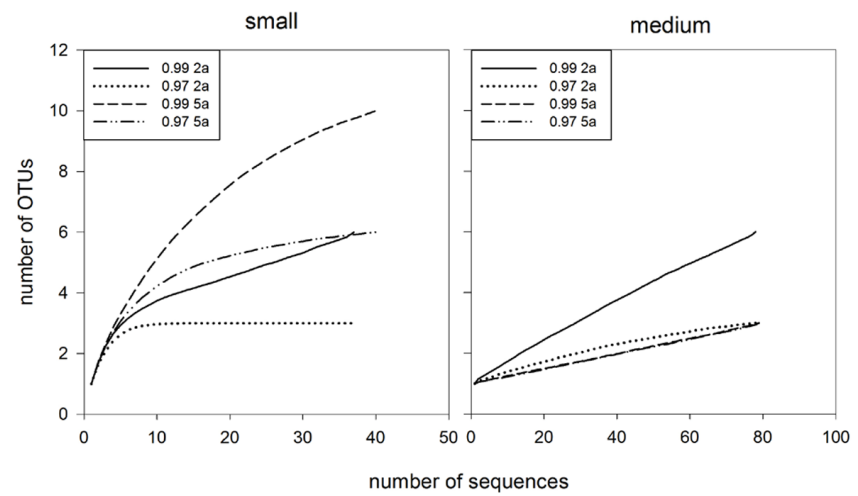

Fig. 3. Rarefaction curves of the different clone libraries of nifH gene sequences. In total sequences were consolidated in 4 groups: 2a small, 2a medium, 5a small and 5a medium. Calculations were made on 99 and $97 \%$ similarity level for the small (left) and the medium (right) sized nodules from plants grown on the $2 \mathrm{a}$ and the 5a site. Calculations were done with mothur v. 1.26.0.

without inoculation of rhizobial strains were studied (Naeem et al., 2004; Wielbo et al., 2010). All developed nodules had an indeterminate shape, which is the typical morphology of a Trifolium-Rhizobium symbiosis (Sadowsky and Graham, 2006; Gage, 2004). It is very likely that the peak of nodule abundance was reached at the time of sampling, because the plant was in the flowering stage where most nitrogen is needed (Malhi et al., 2007). At both sites the majority of nodules was small, which is in line with observation of Zahran et al. (1998), who stated that wild legumes mostly form small nodules. This is attributed to the fact that indigenous rhizobia are often adapted to the harsh environmental conditions but at the same time are less effective in forming the symbiosis (Wielbo et al., 2010).

As the evaluation of the amount and distribution of small, medium and large nodules resulted in no significant difference between plants from the two different sites, the question arose if the symbiotic microbial community of the differently sized nodules differed. To address that question, nifH clone libraries and the influence of soil age on the nodule community were compared.

Clone libraries of the medium sized nodules showed similar diversity pattern for both sites. The community was mainly composed of Rhizobium leguminosarum bv. trifolii, which exclusively formed one OTU (Table 2). R. leguminosarum bv. trifolii is the common and most effective strain infecting Trifolium species (Doyle, 1998). It is known that the plants are able to control nodule size and therefore promote growth of nodules formed by effective rhizobia (Voisin et al., 2010; Kouchi and Yoneyama, 1984). Therefore, one can assume that strains inhabiting medium or large nodules were most competitive and effective in forming the symbiosis. Otherwise nodule growth would not have been promoted by the plant.
However, obviously the medium sized nodules did not drive the difference between the sites. In contrast to the medium sized nodules, Adonis permutation tests revealed a significant influence of soil age on the nifH harboring microbial community of the small sized nodules. The differences are mainly based on an increase of clones coding for $R$. leguminosarum bv. trifolii and in addition to a decrease of species from cluster I. Especially, the amount of clones which harbored the insert of nifH related to OTU5, increased in plants from the 5a site. Assuming that $R$. leguminosarum from OTU5 is the most effective ecotype in nodulating $T$. arvense at this site, the small nodules being composed of $R$. leguminosarum from OTU5 might have had the potential to develop to a medium or large nodule over time. The higher proportion of clones assigned to OTU5 might be attributed to an enrichment effect of those bacteria in the 5a soil, where $T$. arvense was already present in the previous years. As $T$. arvense is an annual plant species nodule inhabiting bacteria are periodically released at the end of the vegetation period (Sadowsky and Graham, 2006). In contrast to inoculated species, which are often replaced by indigenous species until the next vegetation period, naturally occurring rhizobia, which were enriched in the nodules, survive (Sessitsch et al., 2002). Consequently, we assume that the probability of a successful development of an effective legume-Rhizobium symbiosis increased year by year.

It is known that nodules formed in response to the presence of indigenous rhizobia in soil often exhibit a higher diversity (Liu et al., 2007; Zakhia et al., 2006) compared to systems where high numbers of selected rhizobial strains have been inoculated. In the small nodules from the 5a site highest rhizobial diversity was observed. Beside sequences belonging to OTU5, some sequences clustered in OTU6, 7 and 8 as well. These organisms might play an important role to set up optimal conditions for nitrogen fixation in the nodules and improve fitness of effective $R$. leguminosarum bv. trifolii strains. Moreover, the presence of other than Rhizobium sequences (OTU1-4, 9) might influence nodule establishment. As shown for Pseudomonas, Bacillus, Sphingomonas and others this might be due to co-invasion of rhizosphere bacteria (Zakhia et al., 2006; Muresu et al., 2008). Therefore, it is not surprising that similarities with typical species that colonize the rhizosphere of annual plants were found in cluster I. However, the role of non-rhizobial species in nodules is discussed controversially. For example Plazinksi et al. (1985) showed that Azospirillum inhibited the symbiosis of Rhizobium with Trifolium repens. In contrast, the presence of Pseudomonas species can improve nodulation (Bolton et al., 1990). As cluster I was very diverse, it is difficult to figure out the specific role of the sequences found. 


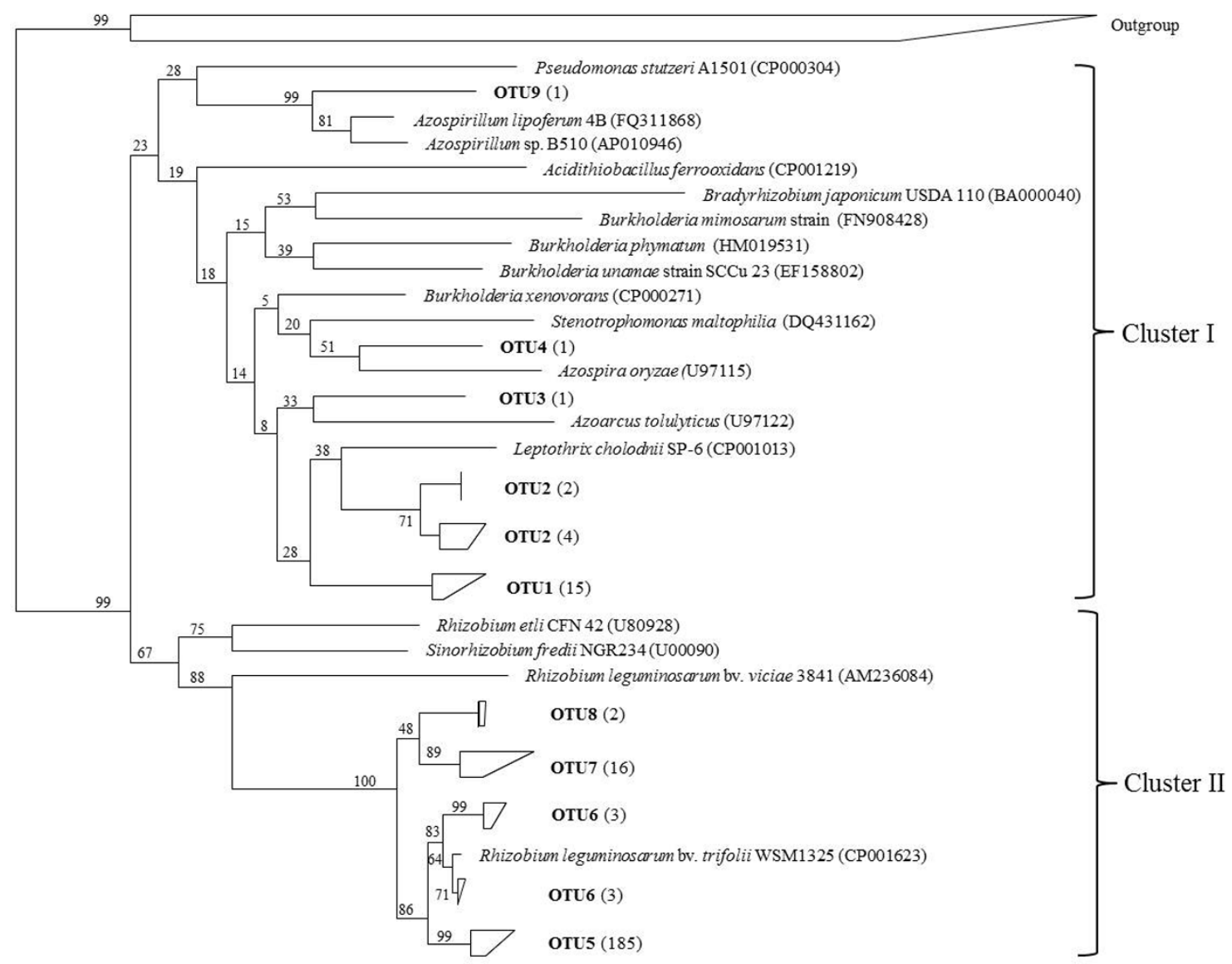

Fig. 4. Phylogenetic tree of the obtained partial nifH gene sequences in comparison to previously published sequences (accession numbers in brackets), analyses were conducted with the ARB software package. The tree was calculated using the neighbor-joining algorithm. Bootstrap values are given in percent next to the branches (1000 replicates). The outgroup is composed of Methanopyrus kandleri AV19 (AE009439), Methanosarcina acetivorans C2A (AE010299) and Clostridium kluyveri DSM 555 (CP000673).

\section{Conclusions}

In summary the data indicate that the plants from the 5a site were more effective in nitrogen fixation, as their nitrogen content was significantly higher, although the ammonium concentrations in soil did not differ significantly. This development might be rather attributed to a change in the legumeRhizobium symbiosis than an overall increase of nodules. In this regard, the hypothesis, that higher nifH diversity can be expected in the nodules from the 2 a soil, was partly disproven. While no difference was observed for the medium nodules Adonis calculations revealed a significant influence of soil age on the diversity of the small nodules. Furthermore the proportion of $R$. leguminosarum bv. trifolii clones was higher at plants from the 5a site, what might be mainly attributed to an enrichment of this bacteria due to the longer $T$. arvense history of this site and might be the reason for the higher nitrogen content in those plants. This study was based on one sampling point in time during the vegetation period. Thus, the dynamic of nodules over time might be a topic of interest for future research, mainly when the size of the nodules can be linked to their particular contribution to nitrogen fixation. Moreover, it would be interesting to address the question if similar observations can be made for perennial legumes like Lotus corniculatus (L.).

\section{Supplementary material related to this article is

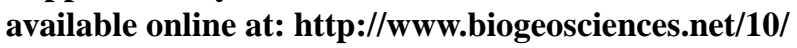 1183/2013/bg-10-1183-2013-supplement.pdf.}

Acknowledgements. This study is part of the Transregional Collaborative Research Centre 38 (SFB/TRR38) which is financially supported by the Deutsche Forschungsgemeinschaft (DFG, Bonn) and the Brandenburg Ministry of Science, Research and Culture (MWFK, Potsdam). We thank Vattenfall Europe Mining AG for providing the research site Chicken Creek.

Additionally, we thank the anonymous reviewers for their helpful comments to improve the manuscript.

Edited by: R. Schulin 


\section{References}

Alexandre, A., Brígido, C., Laranjo, M., Rodrigues, S., and Oliveira, S.: Survey of chickpea rhizobia diversity in Portugal reveals the predominance of species distinct from Mesorhizobium ciceri and Mesorhizobium mediterraneum, Microb. Ecol., 58, 930-941, 2009.

Anyango, B., Wilson, K. J., Beynon, J. L., and Giller, K. E.: Diversity of rhizobia nodulating Phaseolus vulgaris L. in two Kenyan soils with contrasting pHs, Appl. Environ. Microbiol., 61, 4016$4021,1995$.

Bolton, H., Elliott, L., Turco, R., and Kennedy, A.: Rhizoplane colonization of pea seedlings by Rhizobium leguminosarum and a deleterious root colonizing Pseudomonas sp. and effects on plant growth, Plant. Soil, 123, 121-124, 1990.

Boswell, C. C., Lowther, W. L., and Rutherford, A. J.: Symbiotic nitrogen fixation by Trifolium arvense in semi-arid short tussock grasslands, New Zeal. J. Agr. Res., 50, 511-521, 2007.

Crespi, M. and Gálvez, S.: Molecular mechanisms in root nodule development, J. Plant. Growth Regul., 19, 155-166, 2000.

Doyle, J. J.: Phylogenetic perspectives on nodulation: evolving views of plants and symbiotic bacteria, Trends. Plant. Sci., 3, 473-478, 1998.

Elmer, M., Schaaf, W., Biemelt, D., Gerwin, W., and Hüttl, R. F.: The artificial catchment "Chicken Creek" - initial ecosystem development 2005-2010, Research Centre Landscape Development and Mining Landscapes (FZLB), Cottbus, 168 pp., 2011.

Fischer, D., Pfitzner, B., Schmid, M., Simoes-Araujo, J. L., Reis, V. M., Pereira, W., Ormeno-Orrillo, E., Hai, B., Hofmann, A., Schloter, M., Martinez-Romero, E., Baldani, J. I., and Hartmann, A.: Molecular characterisation of the diazotrophic bacterial community in uninoculated and inoculated field-grown sugarcane (Saccharum sp.), Plant. Soil, 356, 83-99, 2012.

Gage, D. J.: Infection and invasion of roots by symbiotic, nitrogenfixing rhizobia during nodulation of temperate Legumes, Microbiol. Mol. Biol. Rev., 68, 280-300, 2004.

Gerwin, W., Schaaf, W., Biemelt, D., Fischer, A., Winter, S., and Hüttl, R. F.: The artificial catchment "Chicken Creek" (Lusatia, Germany) - A landscape laboratory for interdisciplinary studies of initial ecosystem development, Ecol. Eng., 35, 1786-1796, 2009.

Gyaneshwar, P., Hirsch, A. M., Moulin, L., Chen, W.-M., Elliott, G. N., Bontemps, C., Estrada-de los Santos, P., Gross, E., dos Reis, F. B., Sprent, J. I., Young, J. P. W., and James, E. K.: Legume-nodulating Betaproteobacteria: Diversity, host range, and future prospects, Mol. Plant. Microbe. In., 24, 1276-1288, 2011.

Hall, T. A.: BioEdit: a user-friendly biological sequence alignment editor and analysis program for Windows 95/98/NT, Nucleic Acids Symposium Series, 41, 95-98, 1999.

Jacot, K. A., Lüscher, A., Nösberger, J., and Hartwig, U. A.: Symbiotic $\mathrm{N}_{2}$ fixation of various legume species along an altitudinal gradient in the Swiss Alps, Soil Biol. Biochem., 32, 1043-1052, 2000.

Kendzia, G., Reißmann, R., and Neumann, T.: Targeted development of wetland habitats for nature conservation fed by natural inflow in the post-mining landscape of Lusatia, World Min., 2, 88-95, 2008.

Kouchi, H. and Yoneyama, T.: Dynamics of carbon photosynthetically assimilated in nodulated soya bean plants under steady- state conditions 1 . development and application of ${ }^{13} \mathrm{CO}_{2}$ assimilation system at a constant ${ }^{13} \mathrm{C}$ abundance, Ann. Bot., 53, 875-882, 1984.

Krasova-Wade, T. and Neyra, M.: Optimization of DNA isolation from legume nodules, Lett. Appl. Microbiol., 45, 95-99, 2007.

Liu, X., Wang, E., Li, Y., and Chen, W.: Diverse bacteria isolated from root nodules of Trifolium, Crotalaria and Mimosa grown in the subtropical regions of China, Arch. Microbiol., 188, 1-14, 2007.

Ludwig, W., Strunk, O., Westram, R., Richter, L., Meier, H., Yadhukumar, Buchner, A., Lai, T., Steppi, S., Jobb, G., Förster, W., Brettske, I., Gerber, S., Ginhart, A. W., Gross, O., Grumann, S., Hermann, S., Jost, R., König, A., Liss, T., Lüßmann, R., May, M., Nonhoff, B., Reichel, B., Strehlow, R., Stamatakis, A., Stuckmann, N., Vilbig, A., Lenke, M., Ludwig, T., Bode, A., and Schleifer, K. H.: ARB: a software environment for sequence data, Nucle. Acid. Res., 32, 1363-1371, 2004.

Malhi, S. S., Johnston, A. M., Schoenau, J. J., Wang, Z. H., and Vera, C. L.: Seasonal biomass accumulation and nutrient uptake of canola, mustard, and flax on a black chernozem soil in Saskatchewan, J. Plant Nutr., 30, 641-658, 2007.

Markmann, K. and Parniske, M.: Evolution of root endosymbiosis with bacteria: how novel are nodules?, Trends. Plant. Sci., 14, 77-86, 2009.

Muresu, R., Polone, E., Sulas, L., Baldan, B., Tondello, A., Delogu, G., Cappuccinelli, P., Alberghini, S., Benhizia, Y., Benhizia, H., Benguedouar, A., Mori, B., Calamassi, R., Dazzo, F. B., and Squartini, A.: Coexistence of predominantly nonculturable rhizobia with diverse, endophytic bacterial taxa within nodules of wild legumes, FEMS Microbiol. Ecol., 63, 383-400, 2008.

Naeem, F. I., Ashraf, M. M., Malik, K. A., and Hafeez, F. Y.: Competitiveness of introduced Rhizobium strains for nodulation in fodder legumes, Pak. J. Bot., 36, 159-166, 2004.

Opperdoes, F. R. and Lemey, P.: Phylogenetic analysis using protein sequences, in: The Phylogenetic Handbook, 2 Edn, edited by: Lemey, P., Salemi, M., and Vandamme, A.-M., Cambridge University Press, Cambridge, UK, 313-342, 2009.

Perrineau, M. M., Le Roux, C., de Faria, S. M., de Carvalho Balieiro, F., Galiana, A., Prin, Y., and Béna, G.: Genetic diversity of symbiotic Bradyrhizobium elkanii populations recovered from inoculated and non-inoculated Acacia mangium field trials in Brazil, Syst. Appl. Microbiol., 34, 376-384, 2011.

Plazinski, J. and Rolfe, B. G.: Interaction of Azospirillum and Rhizobium strains leading to inhibition of nodulation, Appl. Environ. Microbiol., 49, 990-993, 1985.

Rogel, M. A., Ormeño-Orrillo, E., and Martinez Romero, E.: Symbiovars in rhizobia reflect bacterial adaptation to legumes, Syst. Appl. Microbiol., 34, 96-104, 2011.

Rösch, C., Mergel, A., and Bothe, H.: Biodiversity of denitrifying and dinitrogen-fixing bacteria in an acid forest soil, Appl. Environ. Microbiol., 68, 3818-3829, 2002.

Sadowsky, M. and Graham, P.: Root and stem nodule bacteria of legumes, in: The Prokaryotes, edited by: Dworkin, M., Falkow, S., Rosenberg, E., Schleifer, K.-H., and Stackebrandt, E., Springer Science and Business Media, New York, USA, 818$841,2006$.

Saitou, N. and Nei, M.: The neighbor-joining method: a new method for reconstructing phylogenetic trees, Mol. Biol. Evol., 4, 406$425,1987$. 
Sambrook, J. and Russell, D. W.: Molecular cloning - A laboratory manual, 3 Edn., Cold Spring Harbor Laboratory Press, New York, USA, 2001.

Schaaf, W., Biemelt, D., and Hüttl, R. F.: Initial development of the artificial catchment "Chicken Creek" - monitoring program and survey 2005-2008, Research Centre Landscape Development and Mining Landscapes (FZLB), Cottbus, Germany, 2010.

Schloss, P. D., Westcott, S. L., Ryabin, T., Hall, J. R., Hartmann, M., Hollister, E. B., Lesniewski, R. A., Oakley, B. B., Parks, D. H., Robinson, C. J., Sahl, J. W., Stres, B., Thallinger, G. G., Van Horn, D. J., and Weber, C. F.: Introducing mothur: Open-source, platform-independent, vommunity-supported software for describing and comparing microbial communities, Appl. Environ. Microbiol., 75, 7537-7541, 2009.

Sessitsch, A., Howieson, J. G., Perret, X., Antoun, H., and Romero, M. i.: Advances in Rhizobium research, Crit. Rev. Plant. Sci., 21, 323-378, 2002.

Singh, C. S.: Prevalence of Azospirillum within the stem nodules of Aeschynomene spp. and Neptunia sp., Zentralblatt für Mikrobiologie, 147, 455-458, 1992.

Sotelo, M., Irisarri, P., Lorite, M. J., Casaretto, E., Rebuffo, M. n., SanjuÃn, J., and Monza, J.: Diversity of rhizobia nodulating Lotus corniculatus grown in northern and southern regions of Uruguay, Appl. Soil. Ecol., 49, 197-207, 2011.

Talbi, C., Delgado, M. J., Girard, L., Ramirez-Trujillo, A., Caballero-Mellado, J., and Bedmar, E. J.: Burkholderia phymatum strains capable of nodulating Phaseolus vulgaris are present in Moroccan soils, Appl. Environ. Microbiol., 76, 4587-4591, 2010.
Töwe, S., Albert, A., Kleineidam, K., Brankatschk, R., Dümig, A., Welzl, G., Munch, J., Zeyer, J., and Schloter, M.: Abundance of microbes involved in nitrogen transformation in the rhizosphere of Leucanthemopsis alpina (L.) Heywood grown in soils from different sites of the Damma glacier forefield, Microb. Ecol., 60, 762-770, 2010.

Voisin, A.-S., Munier-Jolain, N., and Salon, C.: The nodulation process is tightly adjusted to plant growth. An analysis using environmentally and genetically induced variation of nodule number and biomass in pea, Plant. Soil, 337, 399-412, 2010.

Wielbo, J., Marek-Kozaczuk, M., Mazur, A., Kubik-Komar, A., and Skorupska, A.: Genetic and metabolic divergence within a Rhizobium leguminosarum bv. trifolii population recovered from clover nodules, Appl. Environ. Microbiol., 76, 4593-4600, 2010.

Zahran, H. H.: Structure of root nodules and nitrogen fixation in Egyptian wild herb legumes, Biologia Plantarum, 41, 575-585, 1998.

Zakhia, F., Jeder, H., Willems, A., Gillis, M., Dreyfus, B., and de Lajudie, P.: Diverse bacteria associated with root nodules of spontaneouslegumes in Tunisia and first report for nifH-like gene within the genera Microbacterium and Starkeya, Microb. Ecol., 51, 375-393, 2006.

Zehr, J. P., Jenkins, B. D., Short, S. M., and Steward, G. F.: Nitrogenase gene diversity and microbial community structure: a crosssystem comparison, Environ. Microbiol., 5, 539-554, 2003. 